\title{
Considerações sobre a constituição do self e da religiosidade na pessoa humana'
}

\author{
Considerations about the constitution of self \\ and religiousness in human person
}

Fernando GENARO JUNIOR 23,4

\section{Resumo}

Este trabalho apresenta considerações sobre a constituição do self e da religiosidade na pessoa humana, a partir de um caso clínico. Empregou-se o método fenomenológico de investigação e foi utilizada a teoria psicanalítica winnicottiana e pós-winnicottiana, a fim de articular e compreender o fenômeno religioso no campo teórico e da clínica psicológica.

Unitermos: Psicanálise. Religiosidade. Self. Winnicott.

\begin{abstract}
The following article introduces the reader to the concept of self and religiousness in human person, based on a clinical case. To this end, the phenomenological method of investigation was used, in addition to Winnicott's psychoanalytical approach and post-winnicottian reading for the purpose of articulating and understanding the religious phenomenon in the theoretical and clinical psychology fields.
\end{abstract}

Uniterms: Psychoanalysis. Religiosity. Self. Winnicott.

Como ponto de partida para o desenvolvimento deste tema, uma indagação se impõe: uma pessoa com impedimentos importantes na constituição do ser e em seu amadurecimento pessoal poderia portar uma experiência religiosa autêntica? Assim, pretende-se destacar algumas questões teórico-clínicas sobre a constituição do self e da religiosidade na pessoa, em uma abordagem fenomenológica de investigação (Bello,
2006, 2004; Critelli, 1996), a partir de um caso clínico. As concepções desenvolvidas por Safra (1999a, 2004, 2006) a respeito da constituição da subjetividade humana estão na base das reflexões aqui enunciadas. Em seu trabalho, Safra procura discriminar e articular as experiências de ordem predominantemente psíquicas, localizadas no nível ôntico da condição humana, daquelas inerentes ao ser humano em seu sentido

\section{urv}

1 Artigo elaborado a partir da dissertação de F. GENARO JUNIOR, intitulada "A questão religiosa na esquizofrenia paranóide". Pontifícia Universidade Católica de São Paulo, 2004.

2 Centro de Referência do Idoso - Zona Norte, Serviço de Psicologia. São Paulo, SP.

3 Universidade Paulista, Curso de Psicologia. CPA-Pompéia, R. Carlos Vicari, 124, Pompéia, 05033-070, São Paulo, SP, Brasil. E-mails: <fgenaro.psico@unip.br;><fernando.genaro@gmail.com>.

4 Pontifícia Universidade Católica de São Paulo, Laboratório de Estudos da Transicionalidade. São Paulo, SP, Brasil.

Agradecimento ao Prof. Dr. Gilberto Safra pelas valiosas contribuições frente ao tema aqui enfocado, assim como sua disponibilidade genuinamente humana. 
universal, aspectos ontológicos da condição humana.

As atividades clínicas do psicólogo permitem que ele se depare, se estiver aberto para isso, com a contundência com que as concepções religiosas atravessam a busca de significado e sentido pelo paciente em estado de sofrimento ou doença, independentemente de ele estar ligado ou não à prática de uma religião, influenciando questões como diagnóstico, restabelecimento e prognóstico. A dissertação de mestrado A questão religiosa na esquizofrenia paranóide (Genaro Jr, 2004), defendida no Departamento de Psicologia Clínica da Pontifícia Universidade Católica de São Paulo, traz uma reflexão sobre as interfaces da experiência religiosa e da constituição do self.

\section{Discriminando campos da experiência religiosa}

Entre os estudiosos do tema, há alguns autores que defendem que o próprio movimento de busca de sentido é religioso em si mesmo, sendo característico da condição humana (Prado, 1999; Safra, 1999b), enquanto outros estudam a religiosidade enquanto expressão cultural e social (Massini, 1999; Paiva, 1999), mas é possível pensar-se que o fenômeno religioso encontra-se imbricado nesses dois registros distintos. No entanto, a busca de sentido é própria da condição ontológica do ser humano, e pode ou não ser contemplada por meio dos aspectos socioculturais. Ou, ainda, pode ou não ser representada e/ou pensada, sempre de forma parcial. Nesse sentido, Amatuzzi (1999) afirma que há uma grande diferença entre a experiência religiosa e a religião instituída, ambas podendo apresentar gradações em suas qualidades de desenvolvimento.

Existem adultos que têm uma concepção religiosa infantil, ingênua, muito pouco pensada ou desenvolvida. Com isso eles desperdiçam energias de uma fonte preciosa para o desenvolvimento humano. Já outros adultos têm uma concepção mais bem desenvolvida. É possível que uma concepção bem desenvolvida exista numa pessoa que não desenvolveu uma experiência religiosa propriamente dita. Ou seja, concepção e experiência nem sempre vão juntas (Amatuzzi, 1999, p.124).

Religião é aqui entendida como "o sistema repre528 sentacional de crenças e dogmas, pelo qual uma pessoa procura modelar sua vida e conduta" (Safra, 2004b), o que envolve compartilhar crenças e doutrinas institucionais. Já religiosidade ou espiritualidade refere-se à experiência singular da pessoa frente ao Absoluto, e que poderá ou não ser vivida em uma dada religião. Retomando Amatuzzi (1999), é possível afirmar que nem sempre a religião de alguém contempla o sentido espiritual que aquela pessoa porta (Safra, 2006).

Não raras vezes encontram-se pessoas que possuem um forte apego às suas crenças (que envolvem nível mental), mas não possuem fé (que diz respeito a um nível existencial), enquanto outros não crêem, mas apresentam profunda fé na existência. Crença é o conjunto de dogmas e conceitos representacionais advindos do trabalho mental, portanto, de caráter cognitivo, enquanto fé é a atitude humana frente à existência, em que há um movimento de arriscar-se em um gesto de entrega frente ao novo (Safra, 2007). No entanto, como elucida Winnicott (1963/1983), fé e crença podem estar intimamente relacionadas:

A uma criança que desenvolve a 'crença em' pode-se
transmitir o deus da casa ou da sociedade que
aconteça ser a sua. Mas para a criança sem nenhuma
'crença em', Deus é na melhor das hipóteses um
truque do pedagogo, e na pior das hipóteses uma
peça de evidência para a criança à qual falta em
relação à figura dos pais confiança no processo de
maturação da natureza humana e cujos pais têm
medo do desconhecido (Winnicott, 1963/1983, p.88,
grifo meu).

Assim sendo, a crença pode ou não ser fruto da fé, sendo a fé reveladora de um saber, enquanto a crença está relacionada ao conhecer. É nesse sentido que Safra (2007) apresenta uma diferença fundamental, tanto teórica quanto clínica: a discriminação entre o saber e o conhecer. Para ele, o saber está intimamente relacionado aos aspectos ontológicos da condição humana, ou seja, aquilo que todo ser humano porta como anseio de si - um pressentimento daquilo de que necessita, sem ainda ter vivido. O conhecer é um construto advindo dos aspectos ônticos, isto é, das experiências vividas e passíveis de representação. Assim, o saber veicula a esperança, e a crença, a confiança, que está mais relacionada a acreditar ou não, fenômeno advindo necessariamente de aspectos já vividos.

Safra (2003), a partir da sua clínica, observa que há uma religiosidade que se manifesta no indivíduo, 
quer ele seja ateu ou religioso. Ter fé não tem necessariamente relação com um sistema de crenças doutrinárias religiosas; trata-se de um movimento originário que busca dar sentido às experiências no mundo. Assim, o próprio movimento de religiosidade encontra-se na raiz da constituição da subjetividade do indivíduo (Safra, 2006).

Nascer é ser atravessado pelas questões e pelo mistério da existência; é conhecer a posição humana e as condições necessárias à instalação de si no mundo com outros. É um conhecimento assentado no surgimento mesmo do acontecer humano. (...) Não se trata simplesmente de um "problema psíquico" ou de "um conflito pulsional", mas de algo que se refere à ontologia do existir humano (Safra, 2004c, p.26, grifo meu).

Para Safra, a subjetividade humana, portanto, acontece nesses dois níveis. O nível ontológico referese às condições prévias que delineiam as possibilidades de cada existência humana, em seus fundamentos da possibilidade do acontecer humano, em seu caráter universal. Do ponto de vista ontológico, o indivíduo está aberto à precariedade, ou seja, à instabilidade do mundo e às questões que atravessam toda a existência humana (Safra, 2004a). Já o nível ôntico refere-se à maneira como empiricamente essa condição ontológica acontece na biografia do indivíduo, ou seja, de que maneira os aspectos ontológicos são singularizados, adquirindo uma configuração individual. O nível ôntico abarca o campo da vida humana, articulado por meio do tempo e do espaço, que são passíveis de representação e de articulação por meio de símbolos e da linguagem compartilhada: "É o registro do factual, daquilo que acontece no mundo, dentro dos registros do tempo e do espaço" (Safra, 2007).

No entanto, ainda que a ontologia diga respeito aos próprios fundamentos da condição humana, ela está para além do tempo e do espaço. Trata-se sempre de um a priori aos aspectos ônticos da experiência humana, apesar de estreitamente dependente destes para sua evidenciação.

Alguns estudiosos da religiosidade tendem a articular esse fenômeno por meio de determinações biológicas, psicológicas e/ou socioculturais, em uma perspectiva desenvolvimentista (Amatuzzi, 1999; Aubert, 2003; Fowler, 1981; Jones, 1991; Meissner, 1996; Rizzuto, 1981). Aqui, aborda-se este tema por outro ângulo: com respaldo nas concepções de Safra sobre a inerência do movimento da religiosidade à constituição da subjetividade, considera-se que qualquer teoria psicológica que venha abordar o tema por via desenvolvimentista/determinista incorre no tamponamento dos sentidos e da própria experiência religiosa.

\section{O impedimento de Paulo: reflexões sobre a constituição do self e da religiosidade}

Esta pesquisa foi realizada com o paciente Paulo(5) em uma de suas internações em unidade de tratamento psiquiátrico. Na época, ele tinha 27 anos, e essa era sua $11^{\mathrm{a}}$ internação. A primeira crise ocorrera no início da adolescência.

O contato deu-se por meio das atividades terapêuticas desenvolvidas na enfermaria masculina do hospital. Assim, não foi realizado um tratamento psicanalítico com Paulo, apenas consultas avulsas a fim de compreender melhor suas queixas e auxiliar a família e a equipe.

Paulo apresentava-se afetivamente distante e falava sempre pautado em um discurso religioso. Sua aparência física era desvitalizada, fato observável pela sua falta de presença. Queixava-se de vários aspectos de sua condição, um deles, suas próprias internações. Manifestava-se de forma agressiva, tanto verbal quanto corporalmente, e ficava muito nervoso em não saber o porquê de tantas internações e tipos de tratamento. Outro aspecto que o deixava absolutamente perturbado era o fato de sua mãe medicá-lo de forma indiscriminada e abusiva em casa, a fim de deixá-lo sempre dopado, ou quando voltava a interná-lo.

Sua mãe era uma pessoa de difícil contato pessoal. Todas as vezes em que se tentou conversar com ela sobre o problema de Paulo, ela tentava converter o pesquisador à sua religião. $\mathrm{O}$ pai de Paulo falecera por problemas cardíacos dez anos antes do momento da pesquisa, causando-Ihe bastante sofrimento.

$\boldsymbol{\nabla \nabla \nabla \nabla}$

S Nome fictício. O paciente referido neste artigo consentiu na utilização do seu material clínico para uso de pesquisa, tendo em vista todas as prerrogativas éticas envolvidas na publicação de caso clínico. Os demais dados foram omitidos para preservar sua identidade. 
Paulo tentou suicídio e atribuiu esse ato não a si mesmo, mas a um "espírito ruim" que havia tentado matá-lo. Em referência ao "espírito ruim", dizia que era o espírito de uma mulher que o atormentava Ihe dizendo que ele não era homem, devido à sua virgindade.

Após a tentativa de suicídio, foi novamente internado e, nesta internação, converteu-se, dentro do próprio hospital, à religião de sua mãe, a pedido dela, para se libertar do "espírito ruim".

Desde então, suas perturbações aumentaram: via escrito no céu o que poderia ou não fazer; lia compulsivamente a Bíblia, mas nada entendia; o "espírito ruim" começou a se manifestar com mais freqüência, questionando-o sobre sua sexualidade, moralidade e fé.

Paulo residia no interior de São Paulo e, quando estava em casa, gostava de ir à igreja, porém suas idas eram restringidas pela mãe. Em uma de suas idas ao culto, dirigiu-se ao pastor e lhe perguntou o que achava da idéia de ele, Paulo, arranjar uma namorada. Tinha a esperança de que, se arranjasse uma namorada, talvez pudesse melhorar o seu estado mental, assim como tinha vontade de ir à praça "paquerar", ter uma casa, enfim, ter um lugar seu. O pastor nada respondeu, deixando-o na mesma.

Suas internações tornaram-se reincidentes e seu comportamento mais nervoso. Jogava objetos contra as paredes em momentos de maior agitação, e gritava: "está amarrado em nome de Jesus" pelos corredores da enfermaria.

Paulo se punia, debatia-se em pensamentos incestuosos com relação a seus irmãos e sua mãe. Em situações mais agudas, gritava "Minha irmã é prostituta! Meus irmãos estão fazendo sexo!". Recitava compulsivamente partes da Bíblia, como o Apocalipse, os Salmos, sem qualquer crítica ou entendimento.

Encontrava-se em uma situação de impedimento que o enlouquecia a ponto de nada conseguir responder por si mesmo. Tudo era conduzido pela mãe: as consultas médicas, os exames, banhos etc.

Do ponto de vista clínico, tomando como base inicialmente os aspectos existenciais do paciente, Paulo apresentava-se em uma situação semelhante à claustrofobia, pois vivia uma experiência de impedimento, não imposta por paredes de concreto, mas pelo excesso de 530 controle por parte da mãe, que resultava em uma impossibilidade de poder constituir qualquer gesto próprio no mundo.

Do ponto de vista fenomenológico, essa vivência equivalente à claustrofobia evidenciava-se por suas tentativas de, literalmente, debater-se contra as paredes nos momentos de maior enlouquecimento, que de alguma forma faziam-no sentir-se encerrado. Sob esse prisma, tratava-se de um indivíduo impedido, sem qualquer possibilidade de ter uma direção na vida, ou seja, sem possibilidade de tomar decisões. Paulo ficou detido em uma experiência enlouquecedora, ou seja, de impedimento em seu devir.

A partir da perspectiva da constituição do self, faceta relacionada diretamente aos aspectos ônticos (biográficos) de uma pessoa, as tarefas iniciais de alojamento da psique no corpo, integração no tempo e espaço e estabelecimento de um senso de continuidade de si mesmo (self) foram impedidas em sua história de vida. Paulo não pôde constituir o que Winnicott (1988) denominou realidade subjetiva, por não poder ir para além do universo psíquico materno.

Winnicott (1975) ensina que o bebê inicialmente está mergulhado em uma total dependência e, nesse momento, precisa criar o objeto que irá suprir suas necessidades, o que só será possível pelo encontro humano. $O$ bebê, por meio de suas tensões instintivas, cria o seio do qual necessita, e a mãe, por sua vez, ofereceo no momento exato: o fenômeno de ilusão acontece, graças ao encontro. É o estado devotado da mãe que Ihe proporciona o desenvolvimento de sua singularidade. De um lado, há um movimento de busca por parte do bebê, por meio de suas tensões instintivas e, por parte da mãe, há um olhar em direção ao seu bebê como ser que ali está. Assim, nesse estágio, a tônica está circunscrita à "criação" do mundo, em virtude do estabelecimento do fenômeno de ilusão, que surge por meio do gesto espontâneo do bebê que cria o que lá já se encontrava.

No caso de Paulo, é possível verificar que, em suas tentativas de ir além do seu estado, não houve alguém humano com quem pudesse se encontrar e, desta forma, não pôde constituir a ilusão - processo de apercepção criativa.

Do ponto de vista do processo constitutivo, é significativo que a manifestação da sintomatologia 
tenha se dado no período da adolescência, período em que, pelo próprio processo natural, a sexualidade começa a emergir, intensificando ainda mais o anseio de ir para o mundo, além de trazer à tona questões vivenciadas nos períodos mais iniciais, isto é, referentes aos estágios mais primitivos da constituição do self (Winnicott, 1988).

Nesse contexto, Paulo parece só ter conseguido "resolver" sua questão por meio do enlouquecimento. Cabe destacar que o enlouquecimento originário de Paulo advém do fato de estar impedido, sendo sua sintomatologia psicótica uma organização defensiva frente ao estado originário.

Para Winnicott (1950/1993), a psicose decorre basicamente de uma falha ambiental, isto é, um distúrbio de deficiência ambiental. Assim, ele esclarece que:

A base da saúde mental é instaurada pela mãe desde a concepção e ao longo dos cuidados comuns por ela dispensados ao seu bebê, em razão de sua motivação especial nesse sentido. A doença mental de tipo psicótico surge a partir de adiamentos e distorções, regressões e confusões nos estágios iniciais do crescimento do conjunto ambiente-indivíduo (Winnicott, 1950/1993, p. 315).

Além do estado de enlouquecimento como forma organizada de fuga dos estados de aniquilamento, percebem-se tentativas de Paulo para livrar-se dessa situação. No entanto, Paulo não conseguiu superar seu impasse diante da necessidade de se realizar e a situação de impedimento experimentada perante a mãe. Permaneceu nesse impasse: a loucura organizada também redundou em um enclausuramento do ser. Nesse sentido, pode-se dizer que se trata de uma situação existencial claustrofóbica.

A sua própria conversão religiosa parece ter sido um caminho que imaginou poder libertá-lo da situação de profunda angústia e ambigüidade. No entanto, acabou colocando-o diante do mesmo impasse: a impossibilidade de vir a ser: o "espírito ruim"se fez presente.

No que tange ao movimento de busca do paciente e seu impedimento pessoal, percebe-se uma relação estreita com a figura materna, redundando em uma onipresença da mãe sobre seu mundo subjetivo e psíquico. Em outros termos, ao invés de a maternagem possibilitar a Paulo poder criar sua subjetividade, ela, a mãe, tomou-o como o seu objeto subjetivo. Desta forma, apesar de Paulo ter nascido biologicamente, observase que não houve a possibilidade de sair de dentro da vida imaginativa da figura materna, o que, de certa forma, durante a entrevista com sua mãe foi possível sentir. Percebia-se que se tratava de uma mulher que tentava, a todo momento, converter o outro ao seu próprio pensamento, tornando-se engolfante, isto é, "devorando a todos" que se aproximavam e impossibilitando o convívio com a alteridade e com as diferenças singulares e pessoais.

Diante desse cenário, Paulo não chegou a alcançar autonomia psíquica. Jamais se separou da mãe, e é nesse sentido que se usa aqui o termo clausura. Assim, Paulo reproduz a forma de ser da mãe; infelizmente sua mãe jamais pôde auxiliá-lo a encontrar outro tipo de perspectiva para além de si mesma. Ela não permitiu que ele encontrasse a própria singularidade e jeito pessoal para conduzir sua própria vida.

A religião acabou reafirmando a mesma situação relacional existente entre mãe e filho. A tentativa de Paulo foi de encontrar na figura de Deus um outro que pudesse libertá-lo. Percebe-se que, nesse movimento de busca por Deus, procurou encontrar uma figura paterna que o orientasse e o autorizasse a transgredir a prisão. Deus inicialmente foi buscado por Paulo como uma figura que pudesse intervir nessa situação, favorecendo uma contraposição à visão materna, isto é, capaz de se interpor ao impasse. No entanto, Deus parece ter-se tornado nada mais do que uma réplica materna. Desta maneira, aquilo que parecia uma saída tornou-se reprodução do impasse existencial - porém com outros agravantes, pois à medida que o jovem se desenvolve, outras necessidades surgem, e a problemática originária ganha complexidade e sofisticação. Nesse aspecto, verificou-se que o paciente estava marcado por um impedimento, e que em sua vida a liberdade se equiparava à aniquilação.

A sexualidade, ao invés de propiciar um movimento para fora, ou seja, para um mundo "não mãe", agravava a sua problemática. Paulo acabava manifestando sua sexualidade de maneira inadequada e fora de contexto, pois toda sua excitação sexual também ficava aprisionada, isto é, voltada para as pessoas com quem convivia. Sua sexualidade voltava-se, fundamentalmente, para sua mãe e sua irmã. 
Em face desse complexo dinamismo, destacase o reaparecimento da proibição e do impedimento. Em função de sua relação com uma figura materna cerceadora, situação também reeditada na religião, Paulo encontrava-se proibido de sair em busca de outras mulheres. Diante da impossibilidade de integração de sua sexualidade, lançava mão de novas dissociações de si mesmo. Assim, surgiu a figura do "espírito ruim", fruto da dissociação da sua própria vitalidade, daquilo que clama pelo anseio de realização.

Do ponto de vista das suas relações com o outro, Paulo não encontrou em seu ambiente familiar e nem na religião instituída alguém humano com quem pudesse se encontrar e sustentar seu gesto singular em busca de constituição.

Seu discurso é de cunho religioso, porém não se pode depreender que, de fato, tenha alcançado a efetivação da sua religiosidade. Na rede de significados oferecida pela religião instituída, há uma tentativa de se apoiar para sofrer menos. No entanto, Paulo acabou vivendo o mesmo sofrimento de antes. As idéias de Deus ou do Mal acabaram reduzindo-se a aspectos do pensamento delirante de Paulo, uma vez que a própria religião apresentou-se como uma extensão do psiquismo engolfante materno.

Entretanto, a despeito dos impedimentos apresentados, ele portava um saber. O saber Ihe dizia o que era necessário viver para salvá-lo desse estado de não-vida, que o levou a uma busca de experiências que pudessem libertá-lo da situação de impasse na qual vivia. Pode-se observar essa busca não só na procura por um Deus-pai que o salvasse, mas também em sua tentativa de encontrar no pastor a figura paterna que autorizasse a sua sexualidade e o seu anseio por um lugar próprio, para além da figura materna. Esse saber brotou a partir do não-vivido, que o atravessou com o anseio de um encontro libertador. Paradoxalmente, foi por meio do impedimento que o saber de Paulo aconteceu, sem que dele pudesse ter se apropriado.

\section{Considerações Finais}

A partir das concepções teóricas, assim como do caso clínico exposto, pode-se afirmar que, em alguns casos, o discurso religioso aparece como tentativa de resolução de um problema exclusivamente psíquico.
No caso de Paulo, o discurso religioso acabou reiterando o impedimento do devir.

O discurso religioso não foi suficiente para auxiliar na sua cura por algumas questões: pelo fato de que não foi um outro para além da mãe; e por não poder encontrar no grupo religioso uma figura que pudesse, transferencialmente, autorizar a possibilidade de ir para fora do universo materno, o que poderia ter sido uma intervenção terapêutica por parte do pastor.

Pode-se dizer que houve inicialmente um pequeno vislumbre sobre a religiosidade por parte de Paulo, isto é, houve o anseio e o movimento de ir além da estagnação existencial em que se encontrava. Quando perguntou ao pastor se, arranjando uma namorada, poderia se curar, na verdade ele pediu ao pastor que sustentasse a sua busca. Nesse sentido, Paulo deu um exemplo sobre a importância clínica e do manejo do analista em se colocar como objeto subjetivo, permitindo que o indivíduo direcione sua busca. Paulo ilustra o entrelaçamento entre transferência e religiosidade, compreendendo-se como religioso tudo aquilo que aparece como anseio de ir além, de ir para um outro estado diferente daquele no qual o indivíduo se encontra.

Retomando a questão inicial e norteadora deste texto, pode-se observar que há um entrelaçamento entre a constituição do selfe da religiosidade. Não se trata de uma compreensão sob a perspectiva desenvolvimental ou cultural, mas está relacionada diretamente às características da própria condição humana. A partir do caso de Paulo, pode-se verificar que, a despeito dos seus impedimentos psíquicos, ônticos, ele portava um saber, ontológico, daquilo que Ihe era mais fundamental. Não pôde, entretanto, alcançar a experiência, pois esta depende fundamentalmente de um outro humano para Ihe fazer frente. Assim, observa-se que ôntico e ontológico paradoxalmente andam juntos, isto é, ambos trazem implicações na vida humana. Em outras palavras, na constituição do self aspectos ônticos atualizam-se "em ato" e, portanto, no registro experiencial, o que permite o acesso às experiências de forma geral, entre elas, a religiosa.

\section{Referências}

Amatuzzi, M. M. (1999). Desenvolvimento psicológico e desenvolvimento religioso: uma hipótese descritiva. In 
M. Massini \& M. Mafhfoud (Orgs.), Diante do mistério: psicologia esenso religioso (pp.123-140). São Paulo: Edições Loyola.

Aubert, M. I. (2003). Produção científica: dissertações e teses do Programa de Estudos Pós-Graduados em Psicologia Clínica da Pontifícia Universidade Católica de São Paulo (1999-2003).

Tese de doutorado não-publicada, Departamento de Psicologia Clínica, Pontifícia Universidade Católica de São Paulo.

Bello, A. A. (2004). Fenomenologia e ciências humanas: psicologia, história e religião. Bauru: EDUSC.

Bello, A. A. (2006). Introdução à fenomenologia. São Paulo: EDUSC.

Critelli, D. M. (1996). Analítica do sentido: uma aproximação e interpretação do real de orientação fenomenológica. São Paulo: Brasiliense.

Fowler, J. W. (1981). Stages of faith: the psychology of human develoment and the quest for meanig. San Francisco: Harper \& Row.

Genaro Junior, F. (2004). Produção científica: dissertações e teses do Programa de Estudos Pós-Graduados em Psicologia Clínica da Pontifícia Universidade Católica de São Paulo (2001-2004). Dissertação de mestrado não-publicada, Departamento de Psicologia Clínica, Pontifícia Universidade Católica de São Paulo.

Jones, W. J. (1991). Contemporary psychoanalysis \& religion: transference and transcendence. New Haven: Yale University Press.

Massini, M. (1999). Conhecimentos psicológicos e experiência religiosa na histótia da cultura luso-brasileira: um sermão de Antônio Vieira. In M. Massini \& M. Mafhfoud (Orgs.), Diante do mistério: psicologia e senso religioso (pp.47-55). São Paulo: Edições Loyola.

Meissner, W. W. (1996). Religion and the clinical pratice of psychology. In E. Shafranske (Org.), The pathology of beliefs of pathology. Washington, DC: American Psychological Association.

Paiva, G. J. (1999). Religião, literatura, e psicologia: o conhecimento pela metáfora. In M. Massini \& M. Mafhfoud (Orgs.), Diante do mistério: psicologia e senso religioso (pp.35-46). São Paulo: Edições Loyola.

Prado, A. (1999). A arte como experiência religiosa. In M. Massini \& M. Mafhfoud (Orgs.), Diante do mistério: psicologia e senso religioso (pp.17-32). São Paulo: Edições Loyola.
Rizzuto, A. M. (1981). The birth of the living God. Chicago: University Press.

Safra, G. (1999a). A face estética do self: teoria e prática (2a ed). São Paulo: Unimarco Editora.

Safra, G. (1999b). Sacralidade e fenômenos transicionais: uma visão winnicottiana. In M. Massini \& M. Mafhfoud (Orgs.), Diante do mistério: psicologia e senso religioso (pp.173-182). São Paulo: Edições Loyola.

Safra, G. (2004a). Aulas ministradas nos cursos: Clínica Winnicottiana e Atividade Programada-III. (Laboratório de Estudos da Transicionalidade - LET). (Aulas ministradas). São Paulo: Pontifícia Universidade Católica de São Paulo.

Safra, G. (2003b). Aulas ministradas no Instituto de Psicologia da Universidade de São Paulo.

Safra, G. (14 de maio 2004b). Palestra no V Seminário de Psicologia e Senso Religioso: Religião e espiritualidade realizado na Pontifícia Universidade Católica de Campinas. Espiritualidade e religiosidade na clínica contemporânea.

Safra, G. (2004c). A po-ética na clínica contemporânea. Aparecida, SP: Idéias \& Letras.

Safra, G. (2006). A hermenêutica na situação clínica: o desvelar da singularidade pelo idioma pessoal. São Paulo: Edições Sobornost.

Safra, G. (2007). Transferência: o estar diante, o estar entre e o estar com. São Paulo: Instituto Sobornost.

Winnicott, D. W. (1975). O brincar e a realidade. Rio de Janeiro: Imago.

Winnicott, D. W. (1983). Moral e educação. In D. W. Winnicott. O ambiente e os processos de maturação: estudos sobre a teoria do desenvolvimento emocional (pp.88-89). Porto Alegre: Artmed. (Originalmente publicada em 1963).

Winnicott, D. W. (1988). Natureza humana. Rio de Janeiro: Imago Editora.

Winnicott, D. W. (1993). A agressividade em relação ao desenvolvimento emocional. In D.W. Winnicott, Textos selecionados: da pediatria a psicanálise (pp.315). Rio de Janeiro: Francisco Alves. (Originalmente publicado em 1950).

Recebido em: 22/2/2006

Versão final reapresentada em: 23/8/2007

Aprovado em: 11/3/2008 